\title{
Optimal Product Quality of Supply Chain Based on Information Traceability in Fashion and Textiles Industry: An Adverse Logistics Perspective
}

\author{
Zhaolin Cheng, ${ }^{1,2}$ Jinghua Xiao, ${ }^{1}$ Kang Xie, ${ }^{1}$ and Xiaoli Huang ${ }^{1}$ \\ ${ }^{1}$ Business School, Sun Yat-sen University, No. 135 Xingang West Road, Guangzhou 510275, China \\ ${ }^{2}$ Economics and Management School, Guangdong Ocean University, Zhanjiang 524088, China \\ Correspondence should be addressed to Jinghua Xiao; xjinghua@gmail.com
}

Received 7 December 2012; Revised 3 February 2013; Accepted 19 February 2013

Academic Editor: Tsan-Ming Choi

Copyright ( $\odot 2013$ Zhaolin Cheng et al. This is an open access article distributed under the Creative Commons Attribution License, which permits unrestricted use, distribution, and reproduction in any medium, provided the original work is properly cited.

\begin{abstract}
This paper investigates and compares two quality control methods, that is, inspection control and traceability control, to optimize supply chain quality in fashion and textiles industry. The objective is to maximize the supply chain participants' expected profits and to achieve a Pareto improvement of supply chain product quality. With quality as a controllable variable indicating the level of opportunistic behavior, the return is interpreted as a function of quality: the higher the quality, the lower the return. Taking into account both quality and inventory quantity, we propose and compare the optimal decision-making models for three control methods of supply chain, respectively: decentralized (no control), inspection, and traceability. Further, we use a numerical example to illustrate the relationships among quality, profits, and quality-control cost coefficients (i.e., inspection-related cost and traceabilityrelated cost). We then analyze and discuss the differences in the applications and scopes of the two control methods. On the one hand, given the poor standardization of fashion and textiles industry in the current practice (especially in China market), the cost of sampling inspection is relatively lower as compared to that of the traceability control method. On the other hand, with the improved industrial standardization and technology, traceability control tends to gain increasing advantages in cost and popularity.
\end{abstract}

\section{Introduction}

Fashion and textiles industry is a major economic sector in developing countries such as China, making significant contributions to economic growth and employment. According to the statistics of WTO (the data is from WTO "International Trade Statistics" database, http://www.wto .org/english/res_e/statis_e/statis_e.htm), in 2011, Chinese fashion and textile export amount is $\$ 248,185$ million, accounting for the highest international market share, 35.2\%, of the fashion and textile export in the whole world $(\$ 706,009$ million in total). However, the competitiveness of Chinese fashion and textiles industry is not as good as we would expect, with its trade competitiveness (TC) indicator decreasing year by year (Hong and Lian [1]).

In this industry, quality is one of the critical competitive factors. As the current competition has evolved to encompass collective performance of the entire supply chain rather than concerning only an individual firm, the concept of "quality" has been extended accordingly to involve the overall product outcome as the result of a chain of successive, interlinked phases: spinning, weaving, apparel, and distribution (Forza and Vinelli [2]). Emerging from various phases of the chain, a number of incidents of product defects have been reported. In 2011, Beijing Consumers' Association revealed that 20 out of 57 inspection samples from ZARA, G2000, Kwunkee, and G-STAR did not meet national industrial standards, regarding aspects such as fiber content, color fastness, formaldehyde, and acidity value. From year 2008 to 2012, we worked with 10 leading Chinese fashion and textiles firms, including Jeanswest, Esquel, and Kam Hing, to improve their supply chain management. According to our study, most investigated manufacturers' procurement cost accounts for $70 \%$ to $80 \%$ of the total cost, meaning that the majority of their product materials have to be acquired from external suppliers. The quality of final products is greatly 
dependent on the quality of these supplies. From our further investigation, most quality defects of fashion and textile products are not caused by technical limitations, but rather by suppliers' malicious opportunistic behaviors to provide defective product materials. Some of these defects are difficult to catch, such as matched materials and cfr. wearability. Thus, many firms try to impose more effective quality procedures and quality control on their suppliers using various methods.

Due to its complexity and uncertainty, quality control of supply chain has posed great challenges to practioners and researchers (Benton and Maloni [3] and Cachon and Lariviere [4]). The existing research of supply chain quality control mainly focuses on two aspects, ex ante controls and ex post controls (Li et al. [5]). Current quality management practice places a greater emphasis on traditional ex ante quality control; it advocates that manufacturers and suppliers formulate quality control contracts to assure and improve quality. Some popular supply chain contracts commonly observed including returns contracts (Savaskan et al. [6]), revenue sharing contracts (Cachon and Lariviere [4]), quantity discount contracts (Peng and Zhou [7]), markdown money contract (Ning et al. [8]), and rebate contracts (Chiu et al. [9]). Zhang and Gerchak [10] considered a joint lot sizing and inspection policy with a random proportion of defective units, where the defective units were replaced by nondefective ones. Salameh and Jaber [11] developed an inventory model for imperfect quality items using the EPQ/EOQ formulae, where they assumed defective items were sold as a single batch at the end of the whole screening process. Liu and Yang [12] investigated a single-stage production system with imperfect process delivering two types of defects: reworkable and nonreworkable items; the reworkable items are sent for reworking, whereas nonreworkable items are immediately discarded by the system. They determined the optimal lot size by maximizing the expected total profit over the expected time length of production cycle. Konstantaras et al. [13] developed a production-inventory model for defective items: selling them to a secondary shop as a single batch at a lower price, or reworking them at an additional cost to restore its originally intended quality.

As supply chain activities become increasingly integrative, researchers began to reexamine the traditional quality management models, structures, and theoretical frameworks, and approach quality control from a whole supply chain perspective. Studies have shown that quality inspection is a basic and direct method for traditional supply chain quality management (Ma and Tang [14], Zhang and Huang [15]), but there are many limitations and difficulties associated with the application of inspection-based contract, such as inability to circumvent opportunistic behaviors in temporary partnerships, imperfect quality inspection technologies (Chan and Wu [16], Brosnan and Sun [17]), and moral hazards (Stump and Heide [18], Maloni and Benton [19]). For fashion and textiles products, some of the defects are elusive and they are hard to detect by observation, which makes the method of inspection either ineffective or too expensive. Chiu et al. [9] explore the performance of sales rebate contracts in fashion supply chains with the use of real empirical data from five companies. The results showed the optimal parameters of the sales rebate contracts should hence be determined with a good balance between the benefit expected profit and the risk variance of profit.

Information technology (IT) developments further expose the limitations of traditional quality control methods especially in complex environments, where traditional inspection-based contract has a difficult time coping with the complex change of the environment and participants' behavior and can hardly control ex post opportunistic behavior. Choi [20] pointed out when the IT cost (such as RFID tag cost) is very small, employing the IT yields an improved supply chain with both larger expected profit and smaller risk. They also found that there existed multiple return policies which can coordinate the supply chain with IT.

Recently more researchers have steered their research towards information traceability-based ex post quality controls (Marucheck et al. [21], Thakur and Donnelly [22], and Carriquiry and Babcock [23]). ISO9001:2000 defines supply chain traceability as the capability of tracing history, tracking both the product status and location by thorough data records captured throughout the supply chain. Trace systems have been applied in product quality control.

In the fashion industry, the adoption of consumer tracing and return is very polarized (especially under the mass customization (MC) service program (Choi et al. [24], Mukhopadhyay and Setoputro [25])). Liu et al. [26] constructed an analytical model with both demand and return uncertainties; they study the optimal policy with three-dimensional decisions on pricing, consumer return, and level of modularity under a mean-variance formulation. From both analytical and numerical analyses, they obtain several important findings and insights. Among others, they argue that the degree of risk aversion of the fashion mass customization (MC) service provider is an influential factor affecting the respective optimal decisions. In addition, Choi [27] examines the optimal return service charge policy in MC service companies. They revealed how the MC service provider's level of risk aversion affects the optimal return service charge policy by comparing two cases-risk-neutral and risk-averse. Wang and $\mathrm{Li}$ [28] built a model to maximize the retailer's profit through a pricing method based on dynamically identified food shelf life. The model was then evaluated with different pricing policies to take advantage of accurate product shelf life information that was captured using innovative tracking and monitoring technologies. Balachandran and Radhakrishnan [29] built a supply chain quality control model where the supply chain final product was made up of components produced by the buyer and components produced by the supplier. Additionally, they examined the different impacts of information tracing on quality control in a single moral-hazard case and a double moral-hazard case. Studies have shown that tracing systems significantly improve quality control (Bechini et al. [30] and Folinas et al. [31]), reduce cost, and promote responsibility sharing (Hobbs [32]).

However, the existing research of information traceability-based quality control has primarily focused on the functions and the structure of information tracing systems (Campos and Hardwick [33], Jansen-Vullers et al. [34], and 
Opara [35]), without investigating how system-based information traceability control influences supply chain partners' opportunistic behavior and what factors play an important role in this process. To address this research gap, this paper sets out to answer the following questions: What are the different factors that influence the choice and application of system-based traceability control and inspection-based quality control? How do these factors (such as quality control cost and punishment) exert different influences on the choice and application of the two methods? Based on the news vendor model, we first develop a principal-agent model for achieving supply chain optimal quality, and then we analyze the applicability and differences between inspection-based traditional quality contracts and system-based information traceability control.

\section{Related Theories and the Basic Model}

Based on examining the related theories, we propose the basic model of this study.

2.1. Resource-Based View, Dynamic Capability View, and Propositions. Resource-based view (RBV) is a well-supported and widely-used theory to interpret a competitive advantage in relation to a firm's resources (Wernerfelt [36]). Many resources are at the disposal of a firm, including total assets, capabilities, organizational processes, firm attributes, information, knowledge, and so on. These resources and capabilities enable the firm to conceive and implement strategies to improve its efficiency and effectiveness (Barney [37]). RBV considers resources as heterogeneous and having limited mobility, which in turn can be transformed into competitive advantages. Barney and Wright [38] pointed out that valuable and rare resources whose benefits can be appropriated by the owning (or controlling) firm provide the firm with a temporary competitive advantage. That advantage can be sustained over longer time periods to the extent that the firm is able to protect against imitation transfer or substitution of the resources.

The early RBV was conceived in a stable setting, not considering environmental changes. As the market and technology changing more and more rapidly, firms need to continuously and dynamically renew their organizational capability. Accordingly, a dynamic capability view (DCV) based on RBV started to form (Teece et al. [39]). With an emphasis on dynamic evolution process, DCV considers advantageous resource forming is a result of accumulating and evolving resources. A firm's core capability is the combined outcome of its tangible and intangible resources integration, technology application, and organizational learning.

From the viewpoint of supply chain, particular resources and capabilities are needed to obtain sustained competitive advantages. On the one hand, the existing resources and capabilities of the supply chain determine its competitive advantages and more or less determine its choice of quality control methods. On the other hand, as the supply chain's internal and external environments change, the supply chain's capabilities change as well, adapting new methods of quality control and forming new competitive advantages. This is a dynamic process keeps evolving with the development of the industry.

By considering some practical scenarios in fashion and textile supply chain quality management, we propose four propositions based on RBV and DCV and later discuss them using models.

(i) Proposition 1: the product type (search product versus experience product) affects the manufacture's choice of quality control methods (inspection versus traceability).

(ii) Proposition 2: the manufacturer's technology capability affects its choice of quality control methods (inspection versus traceability).

(iii) Proposition 3: the standardization level affects the manufacturer's choice of quality control methods (inspection versus traceability).

(iv) Proposition 4: regardless of the quality control method, the manufacturer's optimal strategy of quality control is to impose appropriate punishment measures given the high cost of replacing suppliers.

2.2. Basic Model. The following are assumptions of our basic model.

(1) There is a garment-making supply chain. In an order cycle, supply chain is composed of one supplier and one manufacturer, and the supplier supplies one key part to the manufacturer. The part quality $\varepsilon$ determines the manufacturer's final product quality and $\varepsilon$ is a variable in interval $[0,1]$, for supplier supplying qualified part at a probability of $\varepsilon$ and supplying unqualified part at a probability of $1-\varepsilon$. Both the supplier and the manufacturer are of the make-to-stock (MTS) type. The demand the manufacturer faces is a random variable, and the demand per cycle is independent. We define the demand $D$ as a random variable with a mean $\mu_{1}$.

(2) In one-order cycle, consumers' return because of quality issues is $D_{R}$. Demand and return are independent and identically distributed. With a mean value $\mu_{R}$, the return is a decreasing function of quality $\varepsilon$, which means the higher quality the lower the return. And we assume $\mu_{R}=a_{1}(1-\varepsilon)+b_{1}>0$.

(3) Both the supplier and the manufacturer use the orderup-to strategy. The manufacturer's and the supplier's safe inventories are $s_{S}$ and $s_{M}$, respectively. Without considering the order cost, the quantity of supplier's delivery is $d$. When the quantity does not meet the demand it is considered as shortage; the supplier's shortage cost per unit is $c_{s}^{p}$, the manufacturer's shortage cost per unit is $c_{M}^{p}$, and the supplier's produce cost is $c$.

(4) The supplier's inventory holding cost per unit in one cycle is $k_{S}$, while the manufacturer's inventory holding cost per unit in one cycle is $k_{M}$, where $k_{S}>0$, $k_{M}>0$, the products in transit are considered the 
supplier's inventory cost, if the manufacturer cannot sell out its products, the product salvage value is $c_{M}^{s}$, and $k_{M}+c_{M}^{p}-c_{M}^{s}>0$. Similarly, the supplier's product salvage value is $c_{S}^{s}$, and $k_{s}+c_{s}^{p}-c_{s}^{s}>0$. If the supplier's current inventory cannot supplement the manufacturer's inventory to reach the safe inventory, the supplier is responsible for the shortage cost.

Based on the assumptions above, we can see that as adverse logistics caused by quality issues, the return offsets some demand, the consumers' actual "net demand" $\bar{D}$ is the difference of consumers' demand $D$ and return $D_{R}$. For $D$ and $D_{R}$ being independent and identically distributed and $\bar{D}=$ $D-D_{R}$, we know that $E \bar{D}=\mu_{N}=\mu_{1}-\mu_{R}, \operatorname{var}(\bar{D})=\sigma_{N 1}^{2}=$ $\sigma_{1}^{2}+\sigma_{R}^{2}, \bar{D}$ 's density function is $h(x)$, and distribution function is $H(x)$.

So, the supply chain inventory cost is:

$$
\begin{aligned}
C_{M}^{1}\left(I_{s c}\right) & =k_{M}\left[I_{s c}\right]^{+}+c_{M}^{p}\left[I_{s c}^{1}\right]^{-} \\
& =k_{M} I_{s c}+\left[k_{M}+c_{M}^{p}\right]\left[I_{s c}\right]^{-},
\end{aligned}
$$

where $I_{s c}^{1}$ is the manufacturer's "net inventory," which is equal to the difference value of manufacturer's actual inventory and shortage, is also equal to safe inventory $s_{s c}$ minus consumer's "net demand" $\bar{D} \cdot\left[I_{s c}^{1}\right]^{+}=\max \left\{0, I_{s c}^{1}\right\},\left[I_{s c}^{1}\right]^{-}=\max \left\{0,-I_{s c}^{1}\right\}$. So manufacturer's inventory cost is:

$$
\begin{aligned}
E C_{s c}^{I} & =E C_{s c}^{I}\left(I_{s c}\right)=E C_{s c}^{I}\left(s_{s c}-\bar{D}\right) \\
& =k_{M}\left(s_{s c}-\mu_{N}\right)+\left(k_{M}+c_{M}^{p}\right) \int_{s_{s c}}^{\infty}\left(x-s_{s c}\right) h(x) d x .
\end{aligned}
$$

We assume the supplier's quality cost $v$ is a concave function of quality $\varepsilon$; that is, $\partial v / \partial \varepsilon>0, \partial^{2} v / \partial \varepsilon^{2} \geq 0$, it means the marginal cost of quality is increasing. We assume $v=$ $\alpha_{s} \varepsilon^{2}+\beta_{s}$ (Thatcher and Pingry [40]), so the supply chain whole expected profits is:

$$
\begin{aligned}
E \Pi_{s c}= & p s_{s c}-E C_{s c}^{I}-c_{R} \mu_{R}-v \\
= & (p-c) s_{s c} \\
& -\left(k_{s} \int_{0}^{s_{s c}}\left(s_{s c}-x\right) h(x) d x\right. \\
& \left.\quad+\left(c_{M}^{p}-c_{M}^{s}\right) \int_{s_{s c}}^{\infty}\left(x-s_{s c}\right) h(x) d x\right) \\
& -c_{R} \mu_{R}-v .
\end{aligned}
$$

Lemma 1. $E \Pi_{s c}$ is strictly concave function in defined domain of $\varepsilon_{s c}$ and $s_{s c}$.

Proof. We only need to prove the Hessian Matrix is negative definite.
From formula (3), the Hessian Matrix

$$
\begin{aligned}
& H\left(E \Pi_{s c}\right)=\left[\begin{array}{ll}
\frac{\partial^{2} E \Pi_{s c}}{\partial \varepsilon^{2}} & \frac{\partial^{2} E \Pi_{s c}}{\partial \varepsilon \partial s_{s c}} \\
\frac{\partial^{2} E \Pi_{s c}}{\partial s_{s c} \partial \varepsilon} & \frac{\partial^{2} E \Pi_{s c}}{\partial s_{s c}^{2}}
\end{array}\right] \\
& =\left[\begin{array}{cc}
-2 \alpha_{s} & 0 \\
0 & -\left[k_{M}+c_{M}^{p}-c_{M}^{s}\right] h\left(\lambda_{s c}\right)
\end{array}\right] \text {. }
\end{aligned}
$$

For $\alpha_{s}>0, k_{M}>0, c_{M}^{p}>0$, and $k_{M}+c_{M}^{p}-c_{M}^{s}>0$, while $h\left(\lambda_{s c}\right)$ is probability density function, $h\left(\lambda_{s c}\right)>0$. So, in defined domain the Hessian Matrix satisfied $H_{\varepsilon_{s c} \varepsilon_{s c}}<0$, $H_{s_{M}^{1} s_{M}^{1}}<0, H_{\varepsilon_{s c} \varepsilon_{s c}} H_{s_{s c} s_{s c}}-H_{s_{s c} \varepsilon_{s c}}^{2}>0$, where the Hessian Matrix is negative definite. That means $E \Pi_{s c}$ is strictly concave function in defined domain of $\varepsilon_{s c}$ and $s_{s c}$.

Obviously, formula (3) is a newsvendor issue, so the supply chain optimal inventory is:

$$
s_{s c}^{*}=H^{-1}\left(\lambda_{s c}\right)=\mu_{N}+\Phi^{-1}\left(\lambda_{s c}\right) \sigma_{N} \text {, }
$$

where $\lambda_{s c}=\left(p+c_{M}^{p}-c\right) /\left(p+k_{M}+c_{M}^{p}-c_{M}^{s}\right), \Phi^{-1}(x)$ is standard normal distribution function.

Substitute formula (5) formula (1) and solving the first derivative of the quality, we get:

$$
\begin{aligned}
& \frac{\partial E \Pi_{s c}}{\partial \varepsilon}=c_{R} a_{1}-2 \alpha_{s} \varepsilon \\
& \text { solve it, } \varepsilon_{s c}^{*}=\frac{c_{R} a_{1}}{2 \alpha_{s}}
\end{aligned}
$$

By Lemma 1, we know at point $\left(\varepsilon_{s c}^{*}, s_{s c}^{*}\right), E \Pi_{s c}$ gets max value.

To the supplier, as in decentralized supply chain, the supplier will not respond for any quality problems, the supplier's profits are:

$$
\begin{aligned}
\Pi_{s} & =(w-c) s_{s c}-v \\
& =(w-c)\left(\mu_{1}-\mu_{R}+\Phi^{-1}\left(\lambda_{s c}\right) \sigma_{N}\right)-v .
\end{aligned}
$$

According to the first-order condition, the supplier's optimal quality level satisfied:

$$
\begin{aligned}
& \frac{\partial E \Pi_{s}}{\partial \varepsilon}=a_{1}(w-c)-2 \alpha_{s} \varepsilon=0, \\
& \text { solve it: } \varepsilon_{s}^{*}=\frac{a_{1}(w-c)}{2 \alpha_{s}} .
\end{aligned}
$$

According to its second derivative $\partial^{2} E \Pi_{s} / \partial \varepsilon^{2}=-2 \alpha_{s}<$ 0 , we can get that $\varepsilon_{s}^{*}$ is the supplier's optimal quality level to maximize its profit.

Apparently, if the product is returned to the supplier, the supplier will lose profits, which means $w-c-c_{R}\left\langle 0\right.$, so $\left.\varepsilon_{s c}^{*}\right\rangle$ $\varepsilon_{s}^{*}$. As such, we can arrive at Inference 1: in the decentralized supply chain, the optimal quality level of the whole supply chain is higher than the supplier's optimal quality. 
From Inference 1, we can see that in the decentralized supply chain the supplier will choose optimal quality for its own profit, and the quality is lower than that of the whole supply chain. In accordance with our field study of the 10 leading Chinese fashion and textiles firms factories, when the manufacturers lack effective supervision, the suppliers often do shoddy work, use inferior material, and impair the product quality. With a focus on the opportunistic behavior, in what follows, we further analyze the differences between sampling inspection-based traditional quality control and systembased information traceability control.

\section{The Manufacturer Uses Inspection-Based Quality Control}

To assure products quality, the manufacturer uses the method of sampling inspection to accept or reject the part according to the evaluation result. Let $\theta_{m}$ denote the intensity of the manufacturer's sampling inspection, which means it can detect defective parts and return the defective parts to the supplier with probability $\theta_{m}$, and the returns of consumers are decreasing function of the manufacturer's inspection level. To simplfy the problem, we assume that $\mu_{R 1}=a_{1}(1-\varepsilon)\left(1-\theta_{m}\right)+$ $b_{1}>0$, and the inspection cost $C_{\text {sample }}=\alpha_{m} \theta_{m}^{2}+\beta_{m}$.

Then, we can describe the supply chain optimal quality issue as the principal-agent relationship as follows:

$$
\begin{array}{ll}
\max : & E \Pi_{M}=(p-w) s_{M}-E C_{M}^{1}-c_{R 1} \mu_{R 1}-C_{\text {sample }}, \\
\text { s.t. } & \varepsilon=\arg \max E \Pi_{s} \quad(\mathrm{IR}) \\
& \max E \Pi_{s}>0 \quad(\mathrm{IC}) .
\end{array}
$$
tion.

We solve the principal-agent problem by adverse deriva-

3.1. The Manufacturer's Optimal Safe Inventory. In this case, the manufacturer's inventory cost is:

$$
\begin{aligned}
C_{M}^{1}\left(I_{M}^{1}\right) & =k_{M}\left[I_{M}^{1}\right]^{+}+c_{M}^{p}\left[I_{M}^{1}\right]^{-} \\
& =k_{M} I_{M}^{1}+\left[k_{M}+c_{M}^{p}\right]\left[I_{M}^{1}\right]^{-} .
\end{aligned}
$$

The manufacturer's expected profits is:

$$
\begin{aligned}
E \Pi_{M}= & (p-w) s_{M}-E C_{M}^{1}-c_{R 1} \mu_{R 1}-C_{\text {sample }} \\
= & (p-w) s_{M} \\
& -\left(k_{M} \int_{0}^{s_{M}}\left(s_{M}-x\right) h_{M}(x) d x\right. \\
& \left.\quad+\left(c_{M}^{p}-c_{M}^{s}\right) \int_{s_{M}}^{\infty}\left(x-s_{M}\right) h_{M}(x) d x\right) \\
& \quad-c_{R 1} \mu_{R 1}-\left(\alpha_{m} \theta_{m}^{2}+\beta_{m}\right) .
\end{aligned}
$$

According to first-order condition, we get the safe inventory $s_{M}^{*}$ :

$$
s_{M}^{*}=H^{-1}\left(\lambda_{M}\right)=\mu_{N 1}+\Phi^{-1}\left(\lambda_{M}\right) \sigma_{N 1},
$$

where $\lambda_{M}=\left(p+c_{M}^{p}-w\right) /\left(p+c_{M}^{p}+k_{M}-c_{M}^{s}\right), \Phi^{-1}(x)$ is standard normal distribution function.

Lemma 2. $E \Pi_{M}$ is strictly concave function in defined domain of $\theta_{m}$ and $s_{M}$.

Proof. we only need to prove the Hessian Matrix is negative definite.

From formula (11), the Hessian Matrix

$$
\begin{aligned}
& H\left(E \Pi_{M}\right)=\left[\begin{array}{ll}
\frac{\partial^{2} E \Pi_{M}}{\partial \varepsilon^{2}} & \frac{\partial^{2} E \Pi_{M}}{\partial \varepsilon \partial s_{M}} \\
\frac{\partial^{2} E \Pi_{M}}{\partial s_{M} \partial \varepsilon} & \frac{\partial^{2} E \Pi_{M}}{\partial s_{M}^{2}}
\end{array}\right] \\
& =\left[\begin{array}{cc}
-2 \alpha_{m} & 0 \\
0 & -\left[k_{M}+c_{M}^{p}-c_{M}^{s}\right] h_{M}\left(\lambda_{M}\right)
\end{array}\right] \text {. }
\end{aligned}
$$

For $\alpha_{m}>0, k_{M}>0, c_{M}^{p}>0$ and $k_{M}+c_{M}^{p}-c_{M}^{s}>0$, while $h_{M}\left(\lambda_{M}\right)$ is probability density function, $h_{M}\left(\lambda_{M}\right)>0$. So, in defined domain the Hessian Matrix satisfied $H_{\theta_{m} \theta_{m}}<0$, $H_{s_{M} s_{M}}<0, H_{\theta_{m} \theta_{m}} H_{s_{M} s_{M}}-H_{s_{M} \theta_{m}}^{2}>0$, the Hessian Matrix is negative definite. That means $E \Pi_{M}$ is strictly concave function in defined domain of $\theta_{m}$ and $s_{M}$.

3.2. The Supplier's Optimal Quality Level. As the manufacturer determines its optimal safe inventory, the supplier will determine its product quality due to manufacturer's optimal safe inventory. The supplier is a type of MTS, so its "net demand" is the difference of manufacturer's order (optimal inventory) and returns, that is, $\bar{D}_{s}=s_{M}-D_{S}^{R}$, where $D_{S}^{R}$ is the returns of unqualified products by manufacturer's inspection, obviously, it is a random variable, its distribution density function is $h_{s}(x)$, and its distribution function is $H_{s}(x)$, its mean value is $\mu_{R 2}$, and $\mu_{R 2}$ is a decreasing function of quality and an increasing function of manufacturer's inspection, we assume that $\mu_{R 2}=a_{1}(1-\varepsilon) \theta_{m}+b_{2}$.

The mean value of the supplier's "net demand" $\bar{D}_{s}$ is $E \bar{D}_{s}=\mu_{N 2}=E s_{M}-E D_{S}^{R}=s_{M}-\mu_{R 2}$, its variance is $\sigma_{N 2}^{2}$, and the supplier determines its optimal inventory according to the "net demand." The supplier's inventory cost is:

$$
\begin{aligned}
C_{S}^{1} & =k_{s}\left[I_{s}^{1}\right]^{+}+c_{s}^{p}\left[I_{s}^{1}\right]^{-} \\
& =k_{s}\left[s_{s}-\bar{D}_{s}\right]^{+}+c_{s}^{p}\left[s_{s}-\bar{D}_{s}\right]^{-} .
\end{aligned}
$$

The expected inventory cost is:

$$
E C_{S}^{I}=k_{s} \int_{0}^{s_{s}}\left(s_{s}-x\right) h_{s}(x) d x+c_{s}^{p} \int_{s_{s}}^{\infty}\left(x-s_{s}\right) h_{s}(x) d x
$$

The supplier's profit is:

$$
\Pi_{s}=(w-c) s_{s}-C_{S}^{I}-v-C\left(D_{S}^{R}\right),
$$




$$
\begin{aligned}
E \Pi_{s}= & (w-c) s_{s} \\
& -\left(k_{s} \int_{0}^{s_{s}}\left(s_{s}-x\right) h_{s}(x) d x\right. \\
& \left.\quad+\left(c_{s}^{p}-c_{s}^{s}\right) \int_{s_{s}}^{\infty}\left(x-s_{s}\right) h_{s}(x) d x\right) \\
& -\left(\alpha_{s} \varepsilon^{2}+\beta_{s}\right)-c_{R 2} \mu_{R 2} .
\end{aligned}
$$

According to first-order condition, we can get the supplier's safe inventory:

solve it: $s_{s}^{*}=H_{s}^{-1}\left(\lambda_{s}\right)=\mu_{N 2}+\Phi^{-1}\left(\lambda_{s}\right) \sigma_{N 2}$

$$
=\mu_{N 1}+\Phi^{-1}\left(\lambda_{M}\right) \sigma_{N 1}-\mu_{R 2}+\Phi^{-1}\left(\lambda_{s}\right) \sigma_{N 2}
$$

where $\lambda_{s}=\left(w+c_{s}^{p}-c\right) /\left(w+c_{s}^{p}+k_{s}-c_{s}^{s}\right)$.

Substitute formula (17) formula (15) and solve the first order condition of quality, we get:

$$
\begin{aligned}
\frac{\partial E \Pi_{s}}{\partial \varepsilon}= & \frac{\partial(w-c) s_{s}}{\partial \varepsilon} \\
& -\partial\left(k_{s} \int_{0}^{s_{s}}\left(s_{s}-x\right) h_{N s}(x) d x\right. \\
& \left.\quad+\left(c_{s}^{p}-c_{s}^{s}\right) \int_{s_{s}}^{\infty}\left(x-s_{s}\right) h_{N s}(x) d x\right)\left(\partial s_{s}\right)^{-1} \\
& \times \frac{\partial s_{s}}{\partial \varepsilon}-2 \alpha_{s} \varepsilon+c_{R 2} a_{1} \theta_{m} \\
= & -2 \alpha_{s} \varepsilon+c_{R 2} a_{1} \theta_{m}
\end{aligned}
$$

solve it : $\varepsilon^{*}=\frac{c_{R 2} a_{1} \theta_{m}}{2 \alpha_{s}}$.

Lemma 3. $E \Pi_{S}$ is strictly concave function in defined domain of $\varepsilon$ and $s_{s}$.

Proof. We only need to prove the Hessian Matrix is negative definite.

From formula (16), the Hessian Matrix is

$$
\begin{aligned}
H\left(E \Pi_{S}\right) & =\left[\begin{array}{ll}
\frac{\partial^{2} E \Pi_{S}}{\partial \varepsilon^{2}} & \frac{\partial^{2} E \Pi_{S}}{\partial \varepsilon \partial s_{s}} \\
\frac{\partial^{2} E \Pi_{S}}{\partial s_{s} \partial \varepsilon} & \frac{\partial^{2} E \Pi_{S}}{\partial s_{s}^{2}}
\end{array}\right] \\
& =\left[\begin{array}{cc}
-2 \alpha_{s} & 0 \\
0 & -\left[k_{s}+c_{s}^{p}-c_{s}^{s}\right] h_{s}\left(\lambda_{s}\right)
\end{array}\right] .
\end{aligned}
$$

For $\alpha_{s}>0, k_{s}>0, c_{s}^{p}>0$ and $k_{s}+c_{s}^{p}-c_{s}^{s}>0$, while $h_{s}\left(\lambda_{s}\right)$ is probability density function, $h_{s}\left(\lambda_{s}\right)>0$. So, in defined domain the Hessian Matrix satisfied $H_{\varepsilon \varepsilon}<0$, $H_{s_{s} s_{s}}<0, H_{\varepsilon \varepsilon} H_{s_{s} s_{s}}-H_{s_{s} \varepsilon}^{2}>0$, the Hessian Matrix is negative definite. That means $E \Pi_{s}$ is strictly concave function in defined domain of $\varepsilon$ and $s_{s}$.

According to Lemma 3, we know that at the point $\left(\varepsilon^{*}, s_{s}^{*}\right)$, the supplier's profits are maximized.

3.3. The Manufacturer's Optimal Inspection. Substitute formula (17) in formula (11), and solve the first derivative of inspection, we get:

$$
\begin{aligned}
\frac{\partial E \Pi_{M}}{\partial \theta_{m}}= & (p-w) \frac{\partial s_{m}^{1}}{\partial \theta_{m}}-\frac{\partial E C_{M}^{1}}{\partial \theta_{m}}-\frac{\partial c_{R 1} \mu_{R 1}}{\partial \theta_{m}}-\frac{\partial C_{\text {sample }}}{\partial \theta_{m}} \\
= & -\frac{\partial c_{R 1}\left(a_{1}(1-\varepsilon)\left(1-\theta_{m}\right)+b_{2}\right)}{\partial \theta_{m}}-\frac{\partial C_{\text {sample }}}{\partial \theta_{m}} \\
= & -\frac{\partial c_{R 1}\left(a_{1}\left(1-\left(c_{R 2} a_{1} \theta_{m} / 2 \alpha_{s}\right)\right)\left(1-\theta_{m 1}\right)+b_{2}\right)}{\partial \theta_{m}} \\
& -2 \alpha_{m} \theta_{m} \\
= & c_{R 1} a_{1}\left(1+\frac{c_{R 2} a_{1}}{2 \alpha_{s}}-\frac{c_{R 2} a_{1}}{\alpha_{s}} \theta_{m}\right)-2 \alpha_{m} \theta_{m} .
\end{aligned}
$$

According to first order condition, we get: $\theta_{m}^{*}=$ $\left(2 c_{R 1} a_{1} \alpha_{s}+c_{R 1} c_{R 2} a_{1}^{2}\right) /\left(2 c_{R 1} c_{R 2} a_{1}^{2}+4 \alpha_{s} \alpha_{m}\right)$.

According to Lemma 2 , we know at point $\left(\theta_{m}^{*}, s_{M}^{*}\right)$, manufacturer's profit $E \Pi_{M}$ is maximized, so we can get Inference 2 .

Inference 2. As $\alpha_{s} \alpha_{m}<\left(2 c_{R 1} a_{1} \alpha_{s}+c_{R 1} c_{R 2} a_{1}^{2}\right) / 4(w-c) c_{R 2}-$ $\left(c_{R 1} c_{R 2} a_{1}^{2} / 2\right)$, the inspection-based quality is improved than decentralized supply chain quality.

Proof. Let $\varepsilon^{*}>\varepsilon_{s}^{*}$, we can prove it.

From Inference 2, we know that the manufacturer should choose its quality control behaviors by comparing inspection cost coefficient and consumer's return loss, while the supplier should choose its production quality level by comparing quality cost coefficient and the manufacturer's return loss, as both cost coefficients are small, the supply chain product quality may be improved.

Inference 3. The optimal quality level $\varepsilon^{*}$ is increasing function of $c_{R 1}$ and $c_{R 2}$, optimal inspection $\theta_{m}^{*}$ is increasing function of $c_{R 1}$, increasing function of $c_{R 2}$ as $\alpha_{m}>c_{R 1} a_{1}$, and decreasing function of $c_{R 2}$ as $\alpha_{m}<c_{R 1} a_{1}$.

Proof. We get each of the first deviations as follows:

$$
\frac{\partial \varepsilon^{*}}{\partial c_{R 1}}=\frac{4 c_{R 2} a_{1}^{2} \alpha_{s} \alpha_{m}\left(\alpha_{s}+a_{1}\right)}{2 \alpha_{s}\left(2 c_{R 1} c_{R 2} a_{1}^{2}+4 \alpha_{s} \alpha_{m}\right)^{2}}>0,
$$




$$
\begin{gathered}
\frac{\partial \varepsilon^{*}}{\partial c_{R 2}}=\frac{c_{R 1} a_{1}^{2}\left(4 \alpha_{s}^{2} \alpha_{m}+c_{R 1} c_{R 2}^{2} a_{1}^{3}+4 c_{R 2} a_{1} \alpha_{s} \alpha_{m}\right)}{4 \alpha_{s}\left(c_{R 1} c_{R 2} a_{1}^{2}+2 \alpha_{s} \alpha_{m}\right)^{2}}>0 \\
\frac{\partial \theta_{m}^{*}}{\partial c_{R 1}}=\frac{4 a_{1} \alpha_{s} \alpha_{m}\left(\alpha_{s}+a_{1}\right)}{\left(2 c_{R 1} c_{R 2} a_{1}^{2}+4 \alpha_{s} \alpha_{m}\right)^{2}}>0, \\
\frac{\partial \theta_{m}^{*}}{\partial c_{R 2}}=\frac{4 c_{R 1} a_{1}^{2} \alpha_{s} \alpha_{m}\left(\alpha_{m}-c_{R 1} a_{1}\right)}{\left(2 c_{R 1} c_{R 2} a_{1}^{2}+4 \alpha_{s} \alpha_{m}\right)^{2}} \begin{cases}>0, & \alpha_{m}>c_{R 1} a_{1} \\
<0, & \alpha_{m}<c_{R 1} a_{1} .\end{cases}
\end{gathered}
$$

From Inference 3, we know that as inspection cost is low, inspection and return loss can be an effective complementary; otherwise, if inspection cost is high, the quality control methods of inspection will be restrained.

Then, the manufacturer's profit is:

$$
\begin{aligned}
E \Pi_{M}= & (p-w) s_{M}-E C_{M}^{1}-c_{R 1} \mu_{R 1}-C_{\text {sample }} \\
= & (p-w)\left(\mu_{N 1}+\Phi^{-1}\left(\lambda_{M}\right) \sigma_{N 1}\right) \\
& -\left(k_{M}\left(s_{M}^{1}-\mu_{N 1}\right)+\left(k_{M}+c_{M}^{p}-c_{M}^{s}\right) B\left(s_{M}^{1}\right)\right) \\
& -c_{R 1} \mu_{R 1}-\left(\alpha_{m} \theta_{m}^{2}+\beta_{m}\right),
\end{aligned}
$$

where $B(s)=\int_{s}^{+\infty}(x-s) \phi(x) d x$.

There are different fabrics in garment-making, and each fabric cannot be distinguished easily, the sampling inspection cost is high. In this case, is there other efficient method to control the quality? We considered that the information systembased information traceability might solve the problem.

\section{The Manufacturer Uses Information Traceability-Based Control}

Golan et al. [41] pointed out that firms build traceability systems to improve supply-side management, to increase safety and quality control. In every case, the benefits of traceability translate into larger net revenues for the firm. The benefits include lower-cost distribution systems, reduced recall expenses, and expanded sales of high-value products. The traceability information system and inspection both can motivate the supplier to improve quality, but there are obvious differences between them. Inspection systems motivate the suppliers by generating significant cost when a lot fails inspection and must be scrapped. Traceability system motivates the suppliers by making it possible to allocate the cost of unsafe products to the source (Starbird and Amanor-Boadu [42]).

4.1. The Manufacturer's Optimal Inventory. In the case of traceability-based control, the supplier is responsible for the unqualified products return loss. As the traceability limitation, there are some errors in tracing. That means manufacturer can trace return loss at probability $\theta_{t}$ and bear the whole loss at probability $1-\theta_{t}$. The traceability is higher, trace probability is bigger. The traceability cost is $C_{\text {trace }}$, and $C_{\text {trace }}=\alpha_{t} \theta_{t}^{2}+\beta_{t}$.
As the manufacturer traces the returns, the consumer's returns are $D_{R}^{\prime}$, and the mean value of returns is $\mu_{R 1}^{\prime}=a_{1}(1-$ $\varepsilon)+b_{0} \geq 0$. The manufacturer's net demand is $\bar{D}^{\prime}$, and the mean value of the manufacturer's net demand is $E \bar{D}^{\prime}=\mu_{N 1}^{\prime}=$ $\mu_{1}-\mu_{R 1}^{\prime}=\mu_{1}-a_{1}(1-\varepsilon)-b_{0}$.

The manufacturer's expected inventory cost is:

$$
\begin{aligned}
E C_{M}^{\prime}= & E C_{M}^{\prime}\left(I_{M}^{\prime}\right)=E C_{M}^{\prime}\left(s_{M}^{\prime}-\bar{D}^{\prime}\right) \\
= & k_{M}\left(s_{M}^{\prime}-\mu_{N 1}^{\prime}\right) \\
& +\left(k_{M}+c_{M}^{p}\right) \int_{s_{M^{\prime}}}^{\infty}\left(x-s_{M}^{\prime}\right) h_{M}^{\prime}(x) d x .
\end{aligned}
$$

So, the manufacturer expected profit is:

$$
E \Pi_{M}^{\prime}=(p-w) s_{M}^{2}-E C_{M}^{2}-\left(\alpha_{t} \theta_{t}^{2}+\beta_{t}\right)-c_{R 1} \mu_{R 1}^{\prime}+c_{R 2} \mu_{R 2}^{\prime} .
$$

According to first order condition, the safe inventory $s_{M}^{\prime *}$ satisfied:

$$
\begin{aligned}
& p-w+k_{M}-\left[k_{M}+c_{M}^{p}\right]\left[1-H_{M}^{\prime}\left(s_{M}^{2}\right)\right]=0, \\
& \text { solve it: } s_{M}^{\prime *}=H_{M}^{\prime-1}\left(\lambda_{M}\right)=\mu_{N 1}^{\prime}+\Phi^{-1}\left(\lambda_{M}\right) \sigma_{N 1}^{\prime},
\end{aligned}
$$

where, $\lambda_{M}=\left(p+c_{M}^{p}-w\right) /\left(p+k_{M}+c_{M}^{p}-c_{M}^{s}\right)$

Lemma 4. $E \Pi_{M}^{\prime}$ is strictly concave function in defined domain of $\theta_{t}$ and $s_{M}^{\prime}$.

Proof. we only need to prove the Hessian Matrix is negative definite.

The Hessian Matrix

$$
\begin{aligned}
& H\left(E \Pi_{M}^{\prime}\right)=\left[\begin{array}{ll}
\frac{\partial^{2} E \Pi_{M}^{\prime}}{\partial \theta_{t}^{2}} & \frac{\partial^{2} E \Pi_{M}^{\prime}}{\partial \theta_{t} \partial s_{M}^{\prime}} \\
\frac{\partial^{2} E \Pi_{M}^{\prime}}{\partial s_{M}^{\prime} \partial \theta_{t}} & \frac{\partial^{2} E \Pi_{M}^{\prime}}{\partial s_{M}^{\prime 2}}
\end{array}\right] \\
& =\left[\begin{array}{cc}
-2 \alpha_{t} & 0 \\
0 & -\left[k_{M}+c_{M}^{p}-c_{M}^{s}\right] h_{M}^{\prime}\left(\lambda_{M}\right)
\end{array}\right] \text {. }
\end{aligned}
$$

For $\alpha_{t}>0, k_{M}>0, c_{M}^{p}>0$ and $k_{M}+c_{M}^{p}-c_{M}^{s}>0$, while $h_{M}^{\prime}\left(\lambda_{M}\right)$ is probability density function, $h_{M}^{\prime}\left(\lambda_{M}\right)>0$. So, in defined domain the Hessian Matrix satisfied $H_{\theta_{t} \theta_{t}}<0$, $H_{s_{M}^{\prime} s_{M}^{\prime}}<0, H_{\theta_{t} \theta_{t}} H_{s_{M}^{\prime} s_{M}^{\prime}}-H_{s_{M}^{\prime} \theta_{t}}^{2}>0$, the Hessian Matrix is negative definite. That means $E \Pi_{M}^{\prime}$ is strictly concave function in defined domain of $\theta_{t}$ and $s_{M}^{\prime}$. 
4.2. The Supplier's Optimal Quality Level. The supplier's net demand is $\bar{D}_{s}^{\prime}$, and its mean value is $E \bar{D}_{s}^{\prime}=\mu_{N 2}^{\prime}=E s_{M}^{2}-$ $E D_{S}^{R}=s_{M}^{\prime}-\mu_{R 2}^{\prime}$, variance is $\sigma_{N 2}^{\prime 2}$, where $\mu_{R 2}^{\prime}=\theta_{t} \mu_{R 1}^{\prime}=$ $\theta_{t}\left(a_{1}(1-\varepsilon)+b_{0}\right)$. So supplier's expected profit is:

$$
\begin{aligned}
E & \Pi_{s}^{\prime} \\
= & (w-c) s_{s}^{\prime} \\
& -\left(k_{s} \int_{0}^{s_{s}^{\prime}}\left(s_{s}^{\prime}-x\right) h_{s}^{\prime}(x) d x+c_{s}^{p} \int_{s_{s}^{\prime}}^{\infty}\left(x-s_{s}^{\prime}\right) h_{s}^{\prime}(x) d x\right) \\
& -\left(\alpha_{s} \varepsilon^{2}+\beta_{s}\right)-c_{R 2} \mu_{R 2}^{\prime} .
\end{aligned}
$$

According to first order condition, we can get the supplier's safe inventory $s_{s}^{\prime *}$ which should satisfy:

$$
\begin{gathered}
w-k_{s} H_{s}^{\prime}\left(s_{s}^{\prime}\right)+c_{s}^{p}\left[1-H_{s}^{\prime}\left(s_{s}^{\prime}\right)\right]=0 \\
\text { solve it: } s_{s}^{\prime *}=H_{s}^{\prime-1}\left(\lambda_{s}\right)=\mu_{N 2}^{\prime}+\Phi^{-1}\left(\lambda_{s}\right) \sigma_{N 2}^{\prime},
\end{gathered}
$$

where $\lambda_{s}=\left(w+c_{s}^{p}-c\right) /\left(w+c_{s}^{p}+k_{s}-c_{s}^{s}\right)$.

Substitute formula (31) in formula (29) and solve the first order condition of quality, we get:

$$
\frac{\partial E \Pi_{s}^{\prime}}{\partial \varepsilon}=-2 \alpha_{s} \varepsilon-c_{R 2} \frac{\partial \mu_{R 2}^{\prime}}{\partial \varepsilon}=0 \Longrightarrow-2 \alpha_{s} \varepsilon+c_{R 2} a_{1} \theta_{t}=0,
$$

solve it: $\varepsilon^{*}=\frac{c_{R 2} a_{1} \theta_{t}}{2 \alpha_{s}}$.

Lemma 5. $E \Pi_{s}^{\prime}$ is strictly concave function in defined domain of $\varepsilon$ and $s_{s}^{\prime}$.

Proof. we only need to prove the Hessian Matrix is negative definite.

Assume the Hessian Matrix

$$
\begin{aligned}
H\left(E \Pi_{s}^{\prime}\right) & =\left[\begin{array}{cc}
\frac{\partial^{2} E \Pi_{s}^{\prime}}{\partial \varepsilon^{\prime 2}} & \frac{\partial^{2} E \Pi_{s}^{\prime}}{\partial \varepsilon \partial s_{s}^{\prime}} \\
\frac{\partial^{2} E \Pi_{s}^{\prime}}{\partial s_{s}^{\prime} \partial \varepsilon^{\prime}} & \frac{\partial^{2} E \Pi_{s}^{\prime}}{\partial s_{s}^{\prime 2}}
\end{array}\right] \\
& =\left[\begin{array}{cc}
-2 \alpha_{s} & 0 \\
0 & -\left[k_{s}+c_{s}^{p}-c_{s}^{s}\right] h_{s}^{\prime}\left(\lambda_{s}\right)
\end{array}\right] .
\end{aligned}
$$

For $\alpha_{s}>0, k_{s}>0, c_{s}^{p}>0$ and $k_{s}+c_{s}^{p}-c_{s}^{s}>0$, while $h_{s}^{\prime}\left(\lambda_{s}\right)$ is probability density function, $h_{s}^{\prime}\left(\lambda_{s}\right)>0$. So, in defined domain the Hessian Matrix satisfied $H_{\varepsilon \varepsilon}<0$, $H_{s_{s}^{\prime} s_{s}^{\prime}}<0, H_{\varepsilon \varepsilon} H_{s_{s}^{\prime} s_{s}^{\prime}}-H_{s_{s}^{\prime} \varepsilon}^{2}>0$, the Hessian Matrix is negative definite. That means $E \Pi_{s}^{\prime}$ is strictly concave function in defined domain of $\varepsilon$ and $s_{s}^{\prime}$.

According to Lemma 5, we know $\varepsilon^{\prime *}$ is the supplier's optimal quality level in the case of traceability-based control.
4.3. The Manufacturer's Optimal Traceability. Then, manufacturer's expected profit is:

$$
E \Pi_{M}=(p-w) s_{M}^{\prime}-E C_{M}^{2}-C_{\text {trace }}-c_{R 1} \mu_{R 1}^{\prime}+c_{R 2} \mu_{R 2}^{\prime} .
$$

According to first order condition, we get:

$$
\begin{aligned}
& \frac{\partial E \Pi_{M}}{\partial \theta_{t}}=-2 \alpha_{t} \theta_{t}-\frac{\partial c_{R 1}\left(a_{1}\left(a-\varepsilon^{\prime *}\right)+b_{0}\right)}{\partial \theta_{t}} \\
&+\frac{\partial c_{R 2} \theta_{t}\left(a_{1}\left(a-\varepsilon^{\prime *}\right)+b_{1}\right)}{\partial \theta_{t}} \\
&=-2 \alpha_{t} \theta_{t}-\frac{c_{R 1} c_{R 2} a_{1}^{2}}{2 \alpha_{s}}-\frac{c_{R 2}^{2} a_{1}^{2} 2\left(\theta_{t}-1\right)}{2 \alpha_{s}} \\
& \Longrightarrow-4 \alpha_{t} \theta_{t} \alpha_{s}-c_{R 1} c_{R 2} a_{1}^{2}+c_{R 2}^{2} a_{1}^{2} 2\left(1-\theta_{t}\right)=0, \\
& \text { solve it: } \theta_{t}^{*}=\frac{2 \alpha_{s} c_{R 1}\left(a_{1}+b_{0}\right)-c_{R 1} c_{R 2} a_{1}^{2}}{2 c_{R 2}^{2} a_{1}^{2}+4 \alpha_{s} \alpha_{t}} .
\end{aligned}
$$

So, we get Inference 4 .

Inference 4. As $\alpha_{m}>\left(4 \alpha_{s}\left(2 c_{R 1} a_{1} \alpha_{s}+c_{R 1} c_{R 2} a_{1}^{2}\right) \alpha_{t}-\right.$ $\left.4 c_{R 1} c_{R 2} a_{1}^{2} \alpha_{s}\left(c_{R 1} a_{1}+c_{R 1} b_{0}-c_{R 2} a_{1}\right)+2 c_{R 1} c_{R 2}^{2} a_{1}^{4}\left(c_{R 1}+c_{R 2}\right)\right) /$ $\left(4 \alpha_{s}\left(2 \alpha_{s} c_{R 1}\left(a_{1}+b_{0}\right)-c_{R 1} c_{R 2} a_{1}^{2}\right)\right)$, the quality by information traceability is Pareto improve the quality by sampling inspection.

Proof. Let $\varepsilon^{\prime *}>\varepsilon^{*}$, we can prove it.

Inference 4 means that as the manufacturer's inspection cost coefficient is high, manufacturer would not control product quality by inspection, while information traceability system can control quality more efficiently. The internal failure cost and the external failure cost have significant impacts on inspection results. So it is important to strengthen traceability to control quality of special type products.

Starbird [43] pointed out that for the limitation of sampling inspection, sampling inspection exhibits sampling error, so some unsafe product passes inspection and some safe product does not; inspection effects were limited in some products such as textile products.

Inference 5. the optimal traceability $\theta_{t}^{*}$ is increasing function of $c_{R 1}$ and a decreasing function of $c_{R 2}$. The optimal quality level $\varepsilon^{\prime *}$ is increasing function of $c_{R 1}$. As $c_{R 2} \in\left(0, \overline{c_{R 2}}\right), \varepsilon^{\prime *}$ is increasing function of $c_{R 2}$, as $c_{R 2} \in\left(\overline{c_{R 2}},+\infty\right), \varepsilon^{\prime *}$ is decreasing function of $c_{R 2}$, where

$$
\overline{c_{R 2}}=\frac{\left(a_{1}+b_{0}\right)\left(-2 a_{1} \alpha_{t}+2 \sqrt{\left(a_{1} \alpha_{t}\right)^{2}+2 \alpha_{s} \alpha_{t}\left(a_{1}+b_{0}\right)^{2}}\right)}{2 a_{1}} .
$$


Proof. Solving each first deviation, we get:

$$
\begin{gathered}
\frac{\partial \theta_{t}^{*}}{\partial c_{R 1}}=\frac{2 \alpha_{s}\left(a_{1}+b_{0}\right)-c_{R 2} a_{1}^{2}}{2 c_{R 2}^{2} a_{1}^{2}+4 \alpha_{s} \alpha_{t}}, \\
\text { for } \theta_{t}^{*}=\frac{2 \alpha_{s} c_{R 1}\left(a_{1}+b_{0}\right)-c_{R 1} c_{R 2} a_{1}^{2}}{2 c_{R 2}^{2} a_{1}^{2}+4 \alpha_{s} \alpha_{t}}>0, \\
2 \alpha_{s}\left(a_{1}+b_{0}\right)-c_{R 2} a_{1}^{2}>0, \quad \frac{\partial \theta_{t}^{*}}{\partial c_{R 1}}>0 ; \\
\frac{\partial \theta_{t}^{*}}{\partial c_{R 2}}=\frac{2 c_{R 1} a_{1}^{2}\left(c_{R 2}^{2} a_{1}^{2}-4 c_{R 2} \alpha_{s}\left(a_{1}+b_{0}\right)-2 \alpha_{s} \alpha_{t}\right)}{2\left(c_{R 2}^{2} a_{1}^{2}+2 \alpha_{s} \alpha_{t}\right)^{2}}, \\
\frac{\partial \varepsilon^{\prime *}}{\partial c_{R 1}}=\frac{c_{R 2} a_{1}}{2\left(2 \alpha_{s}\left(a_{1}+b_{0}\right)-c_{R 2} a_{1}^{2}\right)\left(2 c_{R 2}^{2} a_{1}^{2}+4 \alpha_{s} \alpha_{t}\right)}>0 ; \\
\frac{\partial \varepsilon^{\prime *}}{\partial c_{R 2}} \quad \frac{-c_{R 2}\left(4 \alpha_{s}\left(a_{1}+b_{0}\right)-c_{R 2} a_{1}^{2}\right)}{2}, 00 \\
=\frac{c_{R 1} a_{1}\left(-\left(a_{1}+b_{0}\right) a_{1}^{2} c_{R 2}^{2}-2 a_{1}^{2} \alpha_{t} c_{R 2}+2 \alpha_{s} \alpha_{t}\left(a_{1}+b_{0}\right)\right)}{2\left(2 c_{R 2}^{2} a_{1}^{2}+2 \alpha_{s} \alpha_{t}\right)^{2}},
\end{gathered}
$$

obviously, as $c_{R 2} \in\left(0, \overline{c_{R 2}}\right), \partial \varepsilon^{\prime *} / \partial c_{R 2}>0$, as $c_{R 2} \in\left(\overline{c_{R 2}},+\infty\right)$, $\partial \varepsilon^{\prime *} / \partial c_{R 2}<0$, where,

$$
\overline{c_{R 2}}=\frac{\left(a_{1}+b_{0}\right)\left(-2 a_{1} \alpha_{t}+2 \sqrt{\left(a_{1} \alpha_{t}\right)^{2}+2 \alpha_{s} \alpha_{t}\left(a_{1}+b_{0}\right)^{2}}\right)}{2 a_{1}} .
$$

From Inference 5, we know that information traceability and the supplier's return loss can be effectively complementary, as the supplier's return loss is bigger, the manufacturer would tend to decrease information traceability more. It worth noting that if the supplier's return loss is too big $\left(c_{R 2}>\right.$ $\overline{c_{R 2}}$, the manufacturer might excessively decrease traceability. This would make the supplier choose more opportunistic behaviors, and the product quality level is falling.

Then, the manufacturer's expected profit is:

$$
\begin{aligned}
E \Pi_{M}^{\prime}= & (p-w) s_{M}^{\prime}-E C_{M}^{I \prime}-c_{R 1} \mu_{R 2}-C_{\text {trace }} \\
= & (p-w)\left(\mu_{N 2}+\Phi^{-1}\left(\lambda_{M}^{\prime}\right) \sigma_{N 2}\right) \\
& -\left(k_{M}\left(s_{M}^{\prime}-\mu_{N 2}\right)+\left(k_{M}+c_{M}^{p}-c_{M}^{s}\right) B\left(s_{M}^{\prime}\right)\right) \\
& -c_{R 1} \mu_{R 2}-\left(\alpha_{t} \theta_{t}^{2}+\beta_{t}\right)+c_{R 2} \mu_{R 2}^{\prime},
\end{aligned}
$$

where $B(s)=\int_{s}^{+\infty}(x-s) \phi(x) d x$.

As the supply chain profits include some inverse functions of distribution density functions, it is difficult to use the form

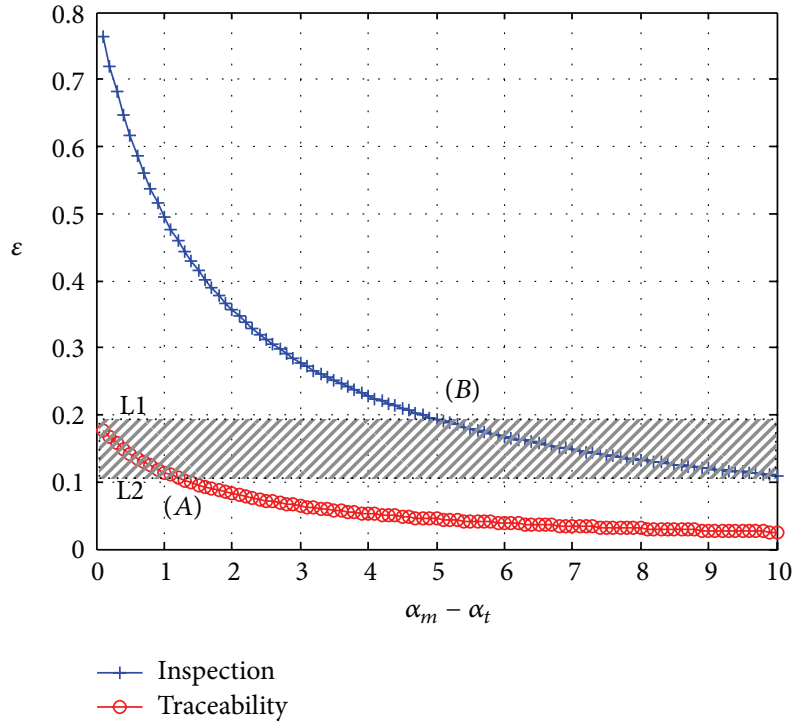

FIGURE 1: Quality control cost coefficients and optimal quality.

of elementary functions expression, so we use a numerical example to analyze how coefficients impact the supply chain partners' profits.

\section{A Numerical Example}

There is a garment-making supply chain consisted of a supplier and a manufacturer; market demands follow a normal distribution $N\left(\mu, \sigma^{2}\right)$; the coefficients are listed in Table 1.

Using the coefficients in Table 1, we use Matlab to do some numerical simulations, to avoid the randomness of the results, we simulate 2000 days' demand for each coefficients change, and solve the mean value of the results, then get the optimal solutions.

In Tables 2 and 3, we can see that as the cost coefficients of quality control increased, manufacturer's profits and optimal quality level is decreasing, while the supplier's profits are increasing. So, the quality control cost coefficients are most important factors impacting on quality control.

From the numerical example, we find that it is obviously difference between the two control method's cost coefficient elasticity. Totally, inspection quality cost coefficient elasticity is bigger than that of information traceability. It makes the manufacturer's and the supplier's profits fluctuated obviously in inspection, while their profits are relatively stable.

Figure 1 shows the relationship between optimal quality level and two quality control method's cost coefficients, the dotted line L1 describes the maximize value of optimal quality level in traceability system, and L2 describes the minimized value of optimal quality level in inspection. From figures, we can see that as quality control coefficients change and make the optimal quality level in the grey area between L1 and L2, the manufacturer can choose either methods to achieve the same optimal quality level, so the area is the pooling equilibrium area. In the area above $\mathrm{L} 1$ and the area below L2, that is $\alpha_{m}<\alpha_{m}(B)$ or $\alpha_{t}>\alpha_{t}(A)$, there must be $\varepsilon^{*}>\varepsilon^{\prime *}$, and the 
TABLE 1: Coefficients' default values.

\begin{tabular}{cccccccccccccc}
\hline$p$ & $w$ & $c$ & $a_{1}$ & $c_{R 1}$ & $c_{R 2}$ & $b_{0}$ & $\mu$ & $c_{M}^{p}$ & $k_{m}$ & $c_{S}^{p}$ & $\alpha_{s}$ & $\alpha_{m}$ & $\alpha_{t}$ \\
\hline 5 & 2 & 1 & 2.5 & 1 & 1 & 1 & 10 & 2 & 3 & 1 & 2 & 3 \\
\hline
\end{tabular}

TABLE 2: Optimal quality level and profits in inspection.

\begin{tabular}{lcccc}
\hline$\alpha_{m}$ & $E \Pi_{M}$ & $E \Pi_{S}$ & $\varepsilon$ & $\theta_{m}$ \\
\hline 1.0 & 14.8939 & 7.7956 & 0.4954 & 0.7927 \\
2.0 & 13.0206 & 8.5516 & 0.3564 & 0.5702 \\
3.0 & 11.6820 & 8.8210 & 0.2783 & 0.4452 \\
4.0 & 10.2489 & 9.2206 & 0.2282 & 0.3652 \\
5.0 & 9.7082 & 9.5677 & 0.1935 & 0.3095 \\
6.0 & 8.9257 & 10.3165 & 0.1679 & 0.2686 \\
7.0 & 8.4090 & 10.3688 & 0.1483 & 0.2372 \\
8.0 & 8.0762 & 10.7888 & 0.1328 & 0.2124 \\
9.0 & 7.7244 & 11.2882 & 0.1202 & 0.1923 \\
10.0 & 7.6513 & 11.2828 & 0.1098 & 0.1757 \\
\hline
\end{tabular}

TABLE 3: Optimal quality level and profits in information traceability.

\begin{tabular}{lcccc}
\hline$\alpha_{t}$ & $E \Pi_{M}$ & $E \Pi_{S}$ & $\varepsilon$ & $\theta_{t}$ \\
\hline 1.0 & 10.3248 & 8.4806 & 0.1143 & 0.1829 \\
2.0 & 10.2712 & 8.4267 & 0.0822 & 0.1316 \\
3.0 & 10.2601 & 8.5109 & 0.0642 & 0.1027 \\
4.0 & 10.1474 & 8.6838 & 0.0527 & 0.0843 \\
5.0 & 10.1730 & 8.6639 & 0.0446 & 0.0714 \\
6.0 & 10.1978 & 8.6755 & 0.0387 & 0.0620 \\
7.0 & 10.2278 & 8.5601 & 0.0342 & 0.0547 \\
8.0 & 10.1112 & 8.8707 & 0.0306 & 0.0490 \\
9.0 & 10.1837 & 8.7118 & 0.0277 & 0.0444 \\
10.0 & 10.0989 & 8.7280 & 0.0253 & 0.0405 \\
\hline
\end{tabular}

manufacturer should choose inspection to control quality, the two areas are separate equilibrium areas.

Figure 2 shows the relationship of the supplier's return loss coefficient and optimal quality level in two cases. Obviously, with $c_{R 2}$ increasing, the optimal quality level of information traceability is decreasing after increasing, this means too high punishment cannot improve products quality efficiently, but play a negative role; the manufacturer should control punishment being smaller than $c_{R 2}(C)$ to control product quality more efficiently.

In Figure 3, it can be seen that that two profit curves intersect at point $\mathrm{E}$, dotted line $\mathrm{L} 3$ describes the maximized profits in information traceability, L3 and inspection curve intersect at point $\mathrm{F}$, the dotted line L4 means the profit level of two profit curves intersect point E. As quality control coefficient changes and makes the manufacturer's optimal profit in the grey area between L3 and L4, the manufacturer can choose either control methods to achieve the same optimal profit, the area is the pooling equilibrium area. In the area above L3, $E \Pi_{M}^{\prime}<E \Pi_{M}$, that is as $\alpha_{m}<\alpha_{m}(F)$, the manufacturer should choose sampling inspection. In the area below L4, the information traceability curve is higher

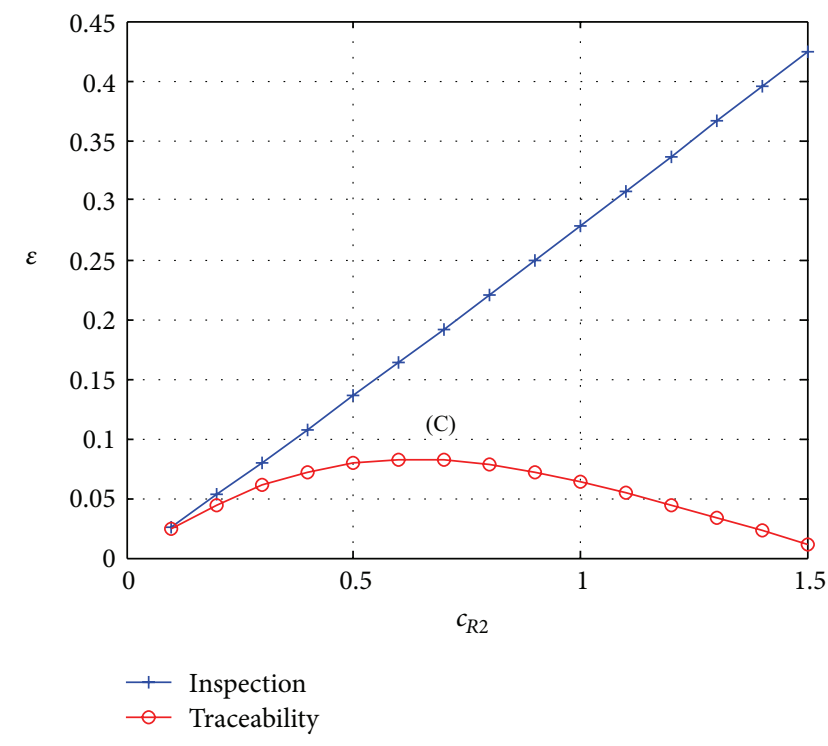

FIgURE 2: The supplier's return loss coefficient and optimal quality.

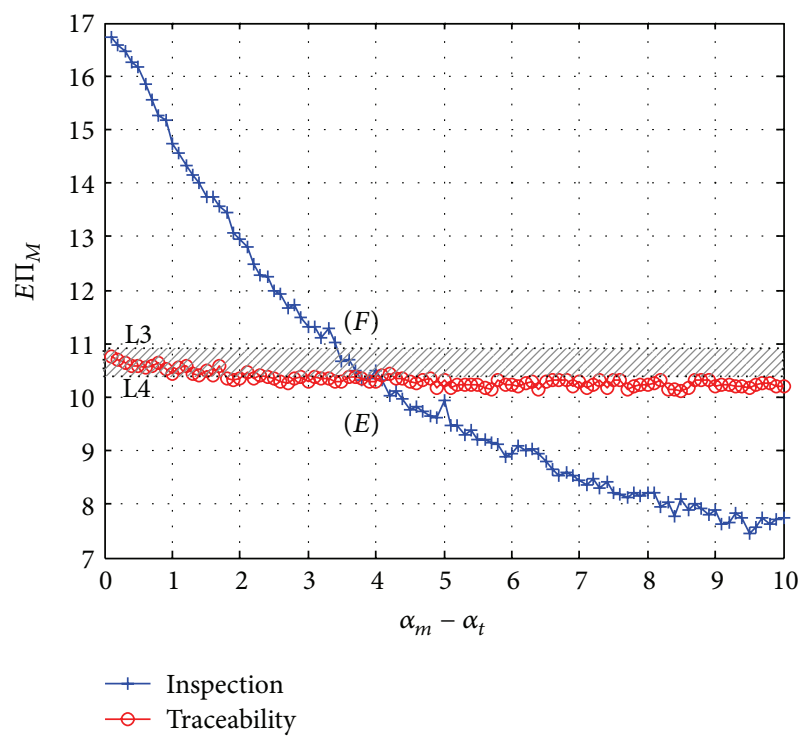

FIGURE 3: Quality control coefficients and the manufacturer's profit.

than sampling inspection curve, as $\alpha_{m}>\alpha_{m}(E)$, the manufacturer's rational selection is information traceability-based control, the two areas are separate equilibrium areas.

Figure 4 shows the relationship between the supplier's return loss coefficient and the manufacturer's profit. We can see that by using information traceability-based control, as the supplier's return loss coefficient increased, the manufacturer's profit is decreasing after increasing. It means that punishment should not be the higher the better, too high 


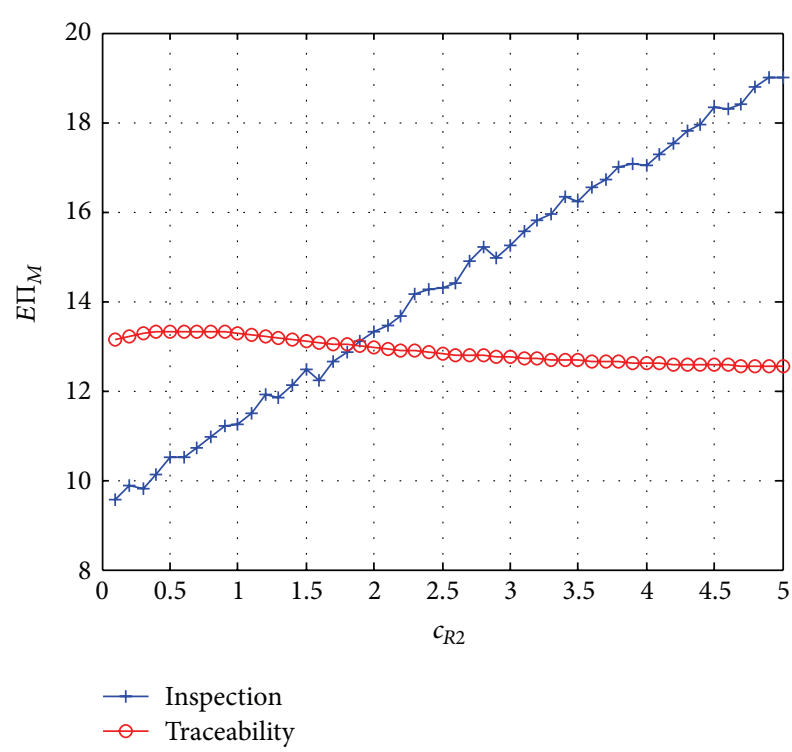

FIGURE 4: The supplier's return loss coefficient and manufacturer's profit.

punishment would decrease optimal quality level and manufacturer's profits. Only a balance between quality control and punishment can achieve quality and profits both Pareto optimal.

\section{Conclusions}

In this paper, we proposed a newsvendor-based adverse logistics model to analyze and compare two different methods of the supply chain quality control, sampling inspection, and traceability information system. From the opportunistic behavior governance perspective, we found that when the supply-chain decision making is decentralized (no control imposed), the supplier would choose the optimal quality level to maximize its own profit. As expected, the supplier's optimal quality level is often lower than that of the whole supply chain. This implies that if the manufacturer does not monitor the supplier's product quality, the supplier tends to make low-quality products even if there is a quality standard imposed. The existence of "double marginalization effect" makes the supplier's opportunistic behavior inevitable. Both the inspection-based and traceability-based quality control methods as discussed in this paper motivate the supplier to improve its product quality. In the proposed model, the quality control cost and the punishment are the key factors; how to get the optimal balance between the two factors is the key to achieve the quality and profit Pareto improvement.

Through examining the model and the numerical example, we compared the two control methods in relation to different influencing factors. First, the product type (search product versus experience product) affects the manufacture's choice of quality control methods. Nelson [44, 45] classified products into search and experience goods according to consumers' ability of determining the product quality before purchase. The manufacturer uses inspection to detect the quality issues and also provide some specific quality information to consumers. This quality information allows consumers to evaluate the product quality before purchase. Thus the inspection-based control is suitable for manufacturing search goods such as shoes. The quality of experience goods such as clothing cannot be easily determined before purchase and need to be "experienced" to fully evaluated. There is often not enough information regarding the quality of experience goods available before purchase. If the experience goods cannot be traced, once there are some quality problems after purchase, manufacturer's reputation and profits will be impacted, and consumers' legitimate interests will not be protected. Therefore, the information traceability control is more suitable for experience goods.

Second, there are important differences between traditional inspection-based control and information traceabilitybased control. On the one hand, there are differences in the action modes of the two quality control methods. Inspection has a control effect before purchase, while information traceability has a control effect after purchase, resulting in different returns and optimal quality levels. As discussed earlier (shown in Inference 3, Inference 5, and the example), with no difference between the cost coefficients of the two quality control methods, inspection control improves quality more effectively (shown in Figure 1). On the other hand, the cost coefficients of the two quality control methods affect the selection between the two methods. While the industry technology capability level and the standardization level will impact the cost coefficients mostly. Given higher technology capability level or higher standardization level of the industry, the data particle size is smaller, information traceability cost coefficient is reduced, and it is cheaper and easier to improve quality using traceability control. Otherwise, inspection control is more cost effective. The standardization level of Chinese fashion and textiles industry is low and lagging behind developed countries. For example, regarding the single combination test method of moisture wicking, 877 relevant standards have been set in USA since 1958, as compared to only 357 relevant standards have been set in China since 1983 . Poor standardization makes data collection more difficult and accordingly the cost of information tracing higher. Currently inspection control is more cost effective in Chinese fashion and textiles industry. It can also explain why IT is lagging in the industry. So we know that manufacturer's technology capability impacts on its quality control methods selection.

The fashion and textiles industry is such a dynamic industry that numerous new materials and accessories are constantly emerging from the market, whose nuance differences are becoming more and more difficult to distinguish by both the manufacturer and the consumer. This poses further challenges to the inspection method, pushing up its cost with limited results and lower reliability. Information system-based traceability control, on the contrary, quickly gains advantage in cost and effectiveness in such situations.

Third, in this paper, there is an implicit assumption that the supplier should not be replaced (the supply chain has only one supplier); in this case, quality control needs to be combined with certain punishment measures. This is consistent with the reality where the cost of supplier replacement is 
often high in the fashion and textiles industry. Regardless of the selected quality control method, the manufacturer should exert optimal punishment measures, not too lenient and not too harsh.

There are two major contributions of the paper: (1) by comparing the choice and applicability of the inspection and traceability control methods, the paper investigates the IT effects on supply chain quality management from an opportunistic behavior governance perspective. Previous studies of primarily analyzed the effects of traditional governance means such as contract, trust and authority on supply chain quality governance, without paying much attention to how information technology impact supply chain quality governance.

(2) The paper explores the underlying reasons for the domination of inspection control over traceability control in current fashion and textiles industry and why IT development is slow. By pointing out the close link between industrial technology and standardization level and the tracing control cost, we predict that there is much room for manufacturer to use IT to improve products quality in fashion and textiles industry in the future. With the improved industrial standardization and technology, traceability control tends to gain increasing advantages in cost and popularity.

Further, in the described principal-agent model, the principal always adjusts its behavior to maximize its own profit, rather than to optimize the overall profit of the whole supply chain. This implies that as the contract condition changes the supply chain may obtain Pareto improvement space, which will be pursued further in our future work.

\section{Acknowledgments}

This work is supported in part by the Natural Science Foundation of China under Grants 71072091 and 71102100, and by the Soft Science Project of Guangdong Province under Grant 2011B070300105.

\section{References}

[1] C. Hong and S. Lian, "Empirical research on international competitiveness of China's fashion and textiles industy," Management and Technology of SME, vol. 12, no. 12, pp. 201-203, 2012.

[2] C. Forza and A. Vinelli, "Time compression in production and distribution within the textile-apparel chain," Integrated Manufacturing Systems, vol. 11, no. 2, pp. 138-146, 2000.

[3] W. C. Benton and M. Maloni, "The influence of power driven buyer/seller relationships on supply chain satisfaction," Journal of Operations Management, vol. 23, no. 1, pp. 1-22, 2005.

[4] G. P. Cachon and M. A. Lariviere, "Supply chain coordination with revenue-sharing contracts: strengths and limitations," Management Science, vol. 51, no. 1, pp. 30-44, 2005.

[5] Y. Y. Li, B. Dan, B. Huang, and G. Guo, "Mechanism design of quality control in assemble-to-order supply chain base on product quality tracing," Computer Integrated Manufacturing Systems, vol. 15, no. 12, pp. 2405-2411, 2009.

[6] R. C. Savaskan, S. Bhattacharya, and L. N. Van Wassenhove, "Closed-loop supply chain models with product remanufacturing," Management Science, vol. 50, no. 2, pp. 239-252, 2004.
[7] H. J. Peng and M. H. Zhou, "Quantity discount supply chain models with fashion products and uncertain yield," Mathematical Problems in Engineering, vol. 2013, Article ID 895784, 11 pages, 2013.

[8] Z. Ning, T. M. Choi, C. Xie, L. Xie, and J. Dai, "Impact of emarketplace on supply chain under markdown policy," Supply Chain Management, vol. 16, no. 6, pp. 409-418, 2011.

[9] C. H. Chiu, T. M. Choi, and H. T. Yeung, "Sales Rebate Contracts in Fashion supply chains," Mathematical Problems in Engineering, vol. 2012, Article ID 908408, 19 pages, 2012.

[10] X. Zhang and Y. Gerchak, "Joint lot sizing and inspection policy in an EOQ model with random yield," IIE Transactions, vol. 22, no. 1, pp. 41-47, 1990.

[11] M. K. Salameh and M. Y. Jaber, "Economic production quantity model for items with imperfect quality," International Journal of Production Economics, vol. 64, no. 1, pp. 59-64, 2000.

[12] J. J. Liu and P. Yang, "Optimal lot-sizing in an imperfect production system with homogeneous reworkable jobs," European Journal of Operational Research, vol. 91, no. 3, pp. 517-527, 1996.

[13] I. Konstantaras, S. K. Goyal, and S. Papachristos, "Economic ordering policy for an item with imperfect quality subject to the in-house inspection," International Journal of Systems Science, vol. 38, no. 6, pp. 473-482, 2007.

[14] S. C. Ma and X. Q. Tang, "Characteristics and strategies of quality management in supply chain," Computer Integrated Manufacturing Systems, vol. 7, no. 9, pp. 32-35, 2001.

[15] C. H. Zhang and X. Y. Huang, "Supply chain quality prevention decision under asymmetric information," Systems EngineeringTheory and Practice, vol. 12, no. 12, pp. 95-99, 2003.

[16] L. K. Chan and M. L. Wu, "Quality function deployment: a literature review," European Journal of Operational Research, vol. 143, no. 3, pp. 463-497, 2002.

[17] T. Brosnan and D. W. Sun, "Improving quality inspection of food products by computer vision-a review," Journal of Food Engineering, vol. 61, no. 1, pp. 3-16, 2004.

[18] R. L. Stump and J. B. Heide, "Controlling supplier opportunism in industrial relationships," Journal of Marketing Research, vol. 33, no. 4, pp. 431-441, 1996.

[19] M. J. Maloni and W. C. Benton, "Supply chain partnerships: opportunities for operations research," European Journal of Operational Research, vol. 101, no. 3, pp. 419-429, 1997.

[20] T. M. Choi, "Coordination and risk analysis of VMI supply chains with RFID technology," IEEE Transactions on Industrial Informatics, vol. 7, no. 3, pp. 497-504, 2011.

[21] A. Marucheck, N. Greis, and C. Mena, "Product safety and security in the global supply chain: issues, challenges and research opportunities," Journal of Operations Management, vol. 29, no. 6, pp. 707-720, 2011.

[22] M. Thakur and K. A. M. Donnelly, "Modeling traceability information in soybean value chains," Journal of Food Engineering, vol. 99, no. 1, pp. 98-105, 2010.

[23] M. Carriquiry and B. A. Babcock, "Reputations, market structure, and the choice of quality assurance systems in the food industry," American Journal of Agricultural Economics, vol. 89, no. 1, pp. 12-23, 2007.

[24] T. M. Choi, N. Liu, S. Ren, and C. L. Hui, "No refund or full refund: when should a fashion brand offer full refund consumer return service for mass customization products?" Mathematical Problems in Engineering, 2013.

[25] S. K. Mukhopadhyay and R. Setoputro, "Optimal return policy and modular design for build-to-order products," Journal of Operations Management, vol. 23, no. 5, pp. 496-506, 2005. 
[26] N. Liu, T. M. Choi, M. C. W. Yuen, and F. Ng, "Optimal pricing, modularity and return policy under mass customization," IEEE Transactions on Systems, Man, and Cybernetics, vol. 42, no. 3, pp. 604-614, 2012.

[27] T. M. Choi, "Optimal return service charging policy for fashion mass customization program," Service Science, 2013.

[28] X. Wang and D. Li, "A dynamic product quality evaluation based pricing model for perishable food supply chains," Omega, vol. 40, no. 6, pp. 906-917, 2012.

[29] K. R. Balachandran and S. Radhakrishnan, "Quality implications of warranties in a supply chain," Management Science, vol. 51, no. 8, pp. 1266-1277, 2005.

[30] A. Bechini, M. G. C. A. Cimino, F. Marcelloni, and A. Tomasi, "Patterns and technologies for enabling supply chain traceability through collaborative e-business," Information and Software Technology, vol. 50, no. 4, pp. 342-359, 2008.

[31] D. Folinas, I. Manikas, and B. Manos, "Traceability data management for food chains," British Food Journal, vol. 108, no. 8, pp. 622-633, 2006.

[32] J. E. Hobbs, "Information asymmetry and the role of traceability systems," Agribusiness, vol. 20, no. 4, pp. 397-415, 2004.

[33] J. G. Campos and M. Hardwick, "A traceability information model for CNC manufacturing," CAD Computer Aided Design, vol. 38 , no. 5 , pp. 540-551, 2006.

[34] M. H. Jansen-Vullers, C. A. Van Dorp, and A. J. M. Beulens, "Managing traceability information in manufacture," International Journal of Information Management, vol. 23, no. 5, pp. 395-413, 2003.

[35] L. U. Opara, "Traceability in agriculture and food supply chain: a review of basic concepts, technological implications, and future prospects," Journal of Food Agricuture and Environment, vol. 1, no. 1, pp. 101-106, 2003.

[36] B. Wernerfelt, "A resource-based view of the firm," Strategic Management Journal, vol. 5, no. 2, pp. 171-180, 2006.

[37] J. B. Barney, "Firm resources and sustained competitive advantage," Journal of Management, vol. 17, no. 1, pp. 99-120, 1991.

[38] J. B. Barney and P. M. Wright, "On becoming a strategic partner: the role of human resources in gaining competitive advantage," Human Resource Management, vol. 37, no. 1, pp. 31-46, 1998.

[39] D. J. Teece, G. Pisano, and A. Shuen, "Dynamic capabilities and strategic management," Strategic Management Journal, vol. 18, no. 7, pp. 509-533, 1997.

[40] M. E. Thatcher and D. E. Pingry, "An economic model of product quality and IT value," Information Systems Research, vol. 15, no. 3, pp. 268-286, 2004.

[41] E. H. Golan, B. Krissoff, F. Kuchler, L. Calvin, K. Nelson, and G. Price, "Traceability in the US food supply: economic theory and industry studies," US Department of Agriculture, Economic Research Service, 2004.

[42] S. A. Starbird and V. Amanor-Boadu, "Do inspection and traceability provide incentives for food safety?" Journal of Agricultural and Resource Economics, vol. 31, no. 1, pp. 14-26, 2006.

[43] S. A. Starbird, "Moral hazard, inspection policy, and food safety," American Journal of Agricultural Economics, vol. 87, no. 1, pp. 15-27, 2005.

[44] P. Nelson, "Advertising as information," The Journal of Political Economy, vol. 82, no. 4, pp. 729-754, 1974.

[45] P. Nelson, "Information and consumer behavior," The Journal of Political Economy, vol. 78, no. 2, pp. 311-329, 1970. 


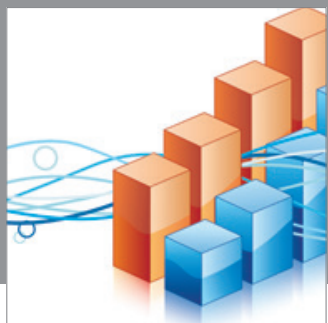

Advances in

Operations Research

mansans

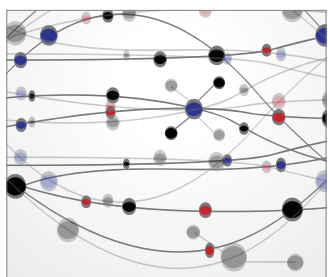

The Scientific World Journal
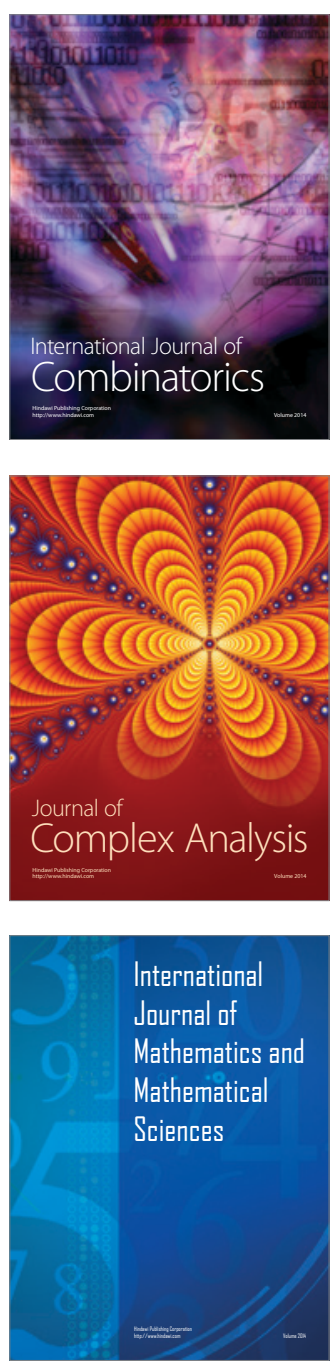
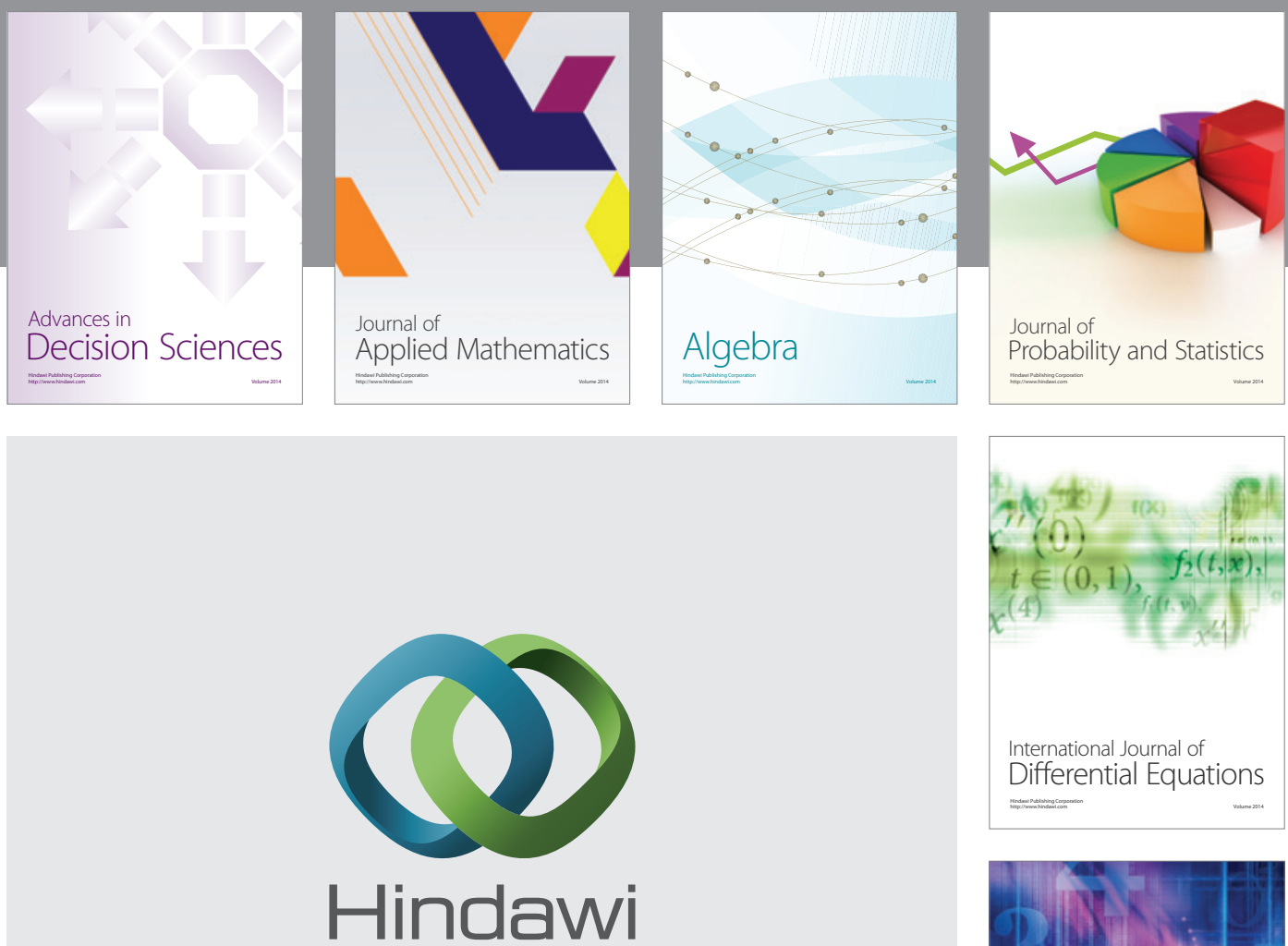

Submit your manuscripts at http://www.hindawi.com
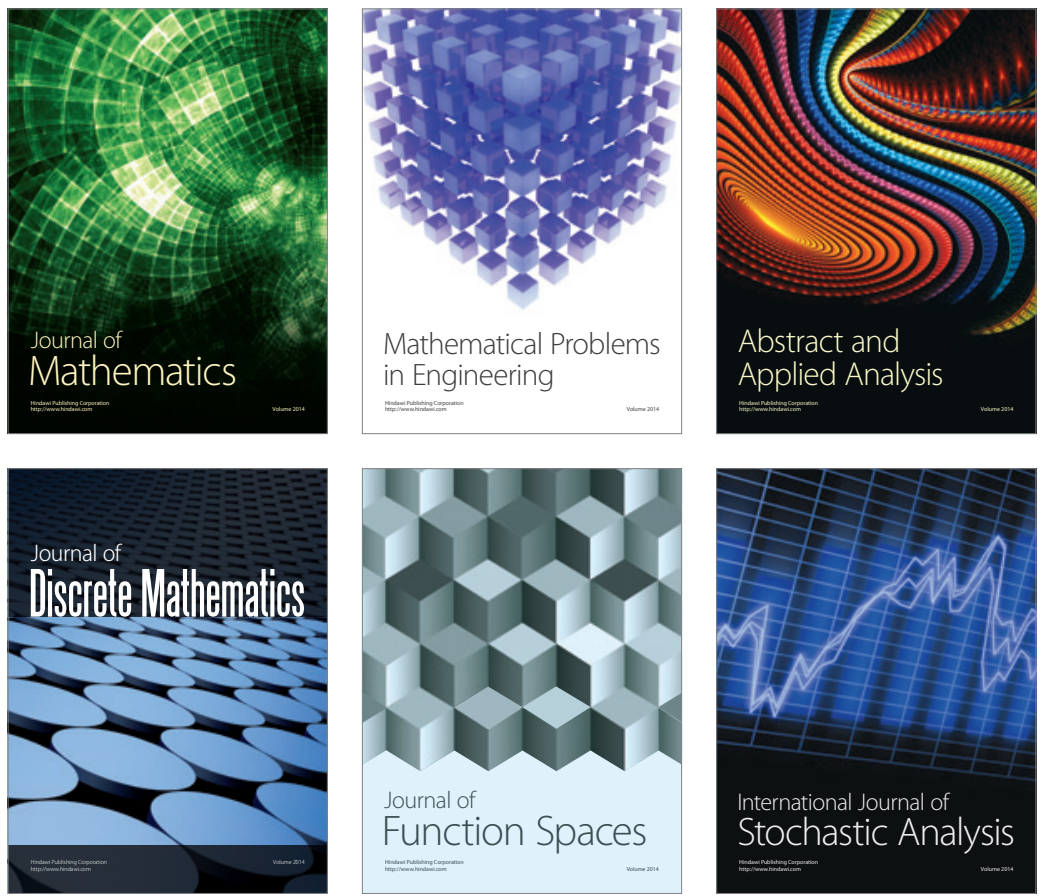

Journal of

Function Spaces

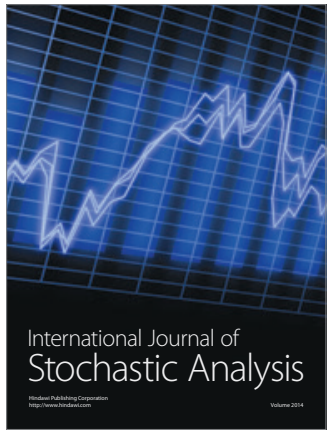

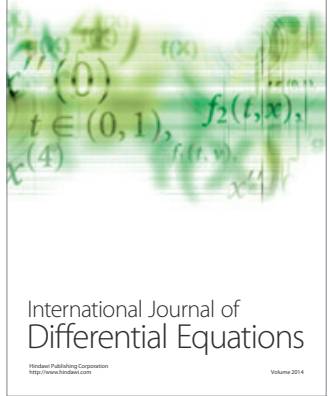
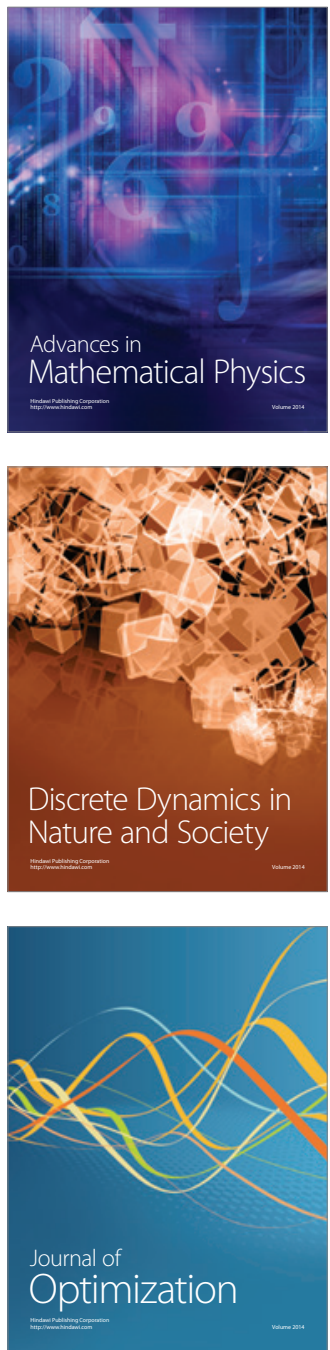